\title{
Synthesis and photoluminescent properties of neodymium-ion doped perovskite oxides
}

\author{
Mohammad Qureshi, Hsin-Yu Chen, Chung-Hsin Lu* \\ Department of Chemical Engineering, National Taiwan University, Taiwan, ROC
}

Received 9 August 2006; received in revised form 8 January 2007; accepted 19 January 2007 by D.D. Sarma

Available online 25 January 2007

\begin{abstract}
The visible transitions of $\mathrm{Nd}^{3+}$ ions were found in the $\mathrm{Nd}_{x}\left(\mathrm{Ca}_{1-x-y-z}, \mathrm{Ba}_{y}, \mathrm{Sr}_{z}\right) \mathrm{TiO}_{3}$ system. All the compositions exhibit a pseudocubic structure. Based on the diffused reflectance spectra, the valence-to-conduction band edge for this system appears at $335 \mathrm{~nm}$. A bright red luminescence at $613 \mathrm{~nm}$ is formed under excitation at $335 \mathrm{~nm}$ for all the compositions with $x=0.002-0.005$. With an increase in the dopant concentration of neodymium ions, the excitation and emission intensities both increase up to $x=0.005$ of neodymium substitution. There is no shift in the excitation and emission spectra of the samples. This report is believed to be the first one in the literature to demonstrate strong visible emission from neodymium-doped oxide systems.
\end{abstract}

(C) 2007 Elsevier Ltd. All rights reserved.

PACS: 78.55.-m; 61.82.Fk; 74.25.Gz

Keywords: A. Semiconductor; D. Optical properties; E. Photoluminescence

\section{Introduction}

The luminescence of $\mathrm{Nd}^{3+}$ ions corresponding to one of the transitions in $4 \mathrm{f}^{n-1} 5 \mathrm{~d}-4 \mathrm{f}^{n}$ requires appropriate host materials that allow the occurrence of visible transitions under ultraviolet excitation conditions [1-3]. Research related to the $4 \mathrm{f}^{n-1} 5 \mathrm{~d}-4 \mathrm{f}^{n}$ transition for various lanthanide ions in $\mathrm{LiYF}_{4}$ and $\mathrm{YPO}_{4}$ has been carried out by Peijzel et al. [4]. In particular, transitions corresponding to ${ }^{4} \mathrm{I}_{9 / 2},{ }^{4} \mathrm{I}_{11 / 2}$ and ${ }^{4} \mathrm{I}_{13 / 2}$ which are in the deep ultraviolet region could be used to enhance emissions in the visible range. Some reports in the literature support the fact that emissions originally in the infrared region can be drastically blue-shifted depending on the kind of host used. For example, substituting strontium ions in the $\mathrm{BaSnO}_{3}$ system unexpectedly leads to a large shift in the band gap and hence the emission color [5].

The ground-state electronic configuration of neodymium is [Xe] $4 \mathrm{f}^{4} 6 \mathrm{~s}^{2}$. The photoluminescence of $\mathrm{Nd}^{3+}$ is ascribed to the $4 f^{2} 5 d^{1}-4 f^{3}$ transition from the excited state to the ground

\footnotetext{
* Corresponding author.

E-mail address: chlu@ntu.edu.tw (C.-H. Lu).
}

state [4]. However, the photoluminescent emission of the above transitions depends significantly on the host materials. In neodymium-ion doped $\mathrm{Y}_{3} \mathrm{Al}_{5} \mathrm{O}_{12}$ (Nd:YAG), an emission is observed at around $1070 \mathrm{~nm}$ in the infrared region [6]. On the other hand, when neodymium ions are doped in $\mathrm{LaGeO}_{3}$, an emission is observed at around $900 \mathrm{~nm}$ in the visible-infrared region [7].

A similar strategy was adopted in this study to synthesize visible emissive compounds by incorporating neodymium ions into the host perovskite. In this study, neodymium ions were doped into perovskite hosts, $(\mathrm{Ca}, \mathrm{Ba}, \mathrm{Sr}) \mathrm{TiO}_{3}$, and the photoluminescent properties of the synthesized materials were analysed. The substitution of neodymium ions in the perovskite host is facilitated owing to the small difference between the ionic sizes of $\mathrm{Ca}^{2+}(1.14 \AA \AA)$ and $\mathrm{Nd}^{3+}(1.27 \AA$ ) . This substitution also satisfies the tolerance factor in perovskite oxides [8]. We found that neodymium-ion doped perovskite oxides produced red luminescence upon $335 \mathrm{~nm}$ excitation. This result adds a new dimension in the study of luminescence in rare-earth doped perovskite oxides. This is believed to be the first study in the literature to report that a strong visible emission is formed in neodymium-ion doped oxide systems. 


\section{Experimental}

Materials with the composition $\mathrm{Nd}_{x}\left(\mathrm{Ca}_{1-x-y-z}, \mathrm{Ba}_{y}\right.$, $\left.\mathrm{Sr}_{z}\right) \mathrm{TiO}_{3}(x=0.002,0.003,0.004$ and 0.005, and corresponding $z=0.018,0.017,0.016$ and 0.015 respectively, keeping the value of $y$ to be 0.01 ) were prepared using a wet chemical method. In this procedure, the first step involved the hydrolyzation of titanium iso-propoxide with an aqueous strontium nitrate solution. Appropriate amounts of $\mathrm{Nd}_{2} \mathrm{O}_{3}$, $\mathrm{BaCO}_{3}$ and $\mathrm{CaCO}_{3}$ were dissolved in dilute $\mathrm{HNO}_{3}$ to form the corresponding nitrate solution. All the ingredients were mixed and stirred for $2 \mathrm{~h}$, followed by drying of the mixed solution at $80{ }^{\circ} \mathrm{C}$. The dried precursors were calcined at $900{ }^{\circ} \mathrm{C}$ in air for $10 \mathrm{~h}$. The resulting powders were further heated at $1350{ }^{\circ} \mathrm{C}$ for $10 \mathrm{~h}$. The $\mathrm{x}$-ray diffraction (XRD) patterns of the samples were recorded using an $\mathrm{x}$-ray diffractometer (MAC MO3 XHF) using $\mathrm{Cu} \mathrm{K} \alpha$ irradiation. The microstructures of the prepared powders were examined using a scanning electron microscope (Hitachi-S 800). Photoluminescent and diffused reflectance measurements were carried out using a fluorescence spectrophotometer (Hitachi-4500) and an ultraviolet-visible (UV-VIS) spectrophotometer (Hitachi-U3410), respectively. Commission Internationale de l'Eclairage (CIE) analysis was performed by employing a fluorescence spectrophotometer (Hitachi-F 4500) with an Ocean Optics CIE analyser attachment.

\section{Results and discussions}

Fig. 1 shows the powder $x$-ray diffraction patterns of the samples with $x=0.002,0.003,0.004$, and $0.005 \mathrm{~mol} \%$ of $\mathrm{Nd}^{3+}$ substitution in $\mathrm{Nd}_{0.002}\left(\mathrm{Ca}_{0.97} \mathrm{Ba}_{0.01} \mathrm{Sr}_{0.018}\right) \mathrm{TiO}_{3}$, $\mathrm{Nd}_{0.003}\left(\mathrm{Ca}_{0.97} \mathrm{Ba}_{0.01} \mathrm{Sr}_{0.017}\right) \mathrm{TiO}_{3}, \mathrm{Nd}_{0.004}\left(\mathrm{Ca}_{0.97} \mathrm{Ba}_{0.01} \mathrm{Sr}_{0.016}\right)$ $\mathrm{TiO}_{3}$, and $\mathrm{Nd}_{0.005}\left(\mathrm{Ca}_{0.97} \mathrm{Ba}_{0.01} \mathrm{Sr}_{0.015}\right) \mathrm{TiO}_{3}$. The XRD pattern for the sample without $\mathrm{Nd}$-ion doping $\left(\left(\mathrm{Ca}_{0.97} \mathrm{Ba}_{0.01} \mathrm{Sr}_{0.02}\right)\right.$ $\left.\mathrm{TiO}_{3}\right)$ is also included in Fig. 1(a). All the patterns of the above compositions are well consistent with the data for tetragonal perovskite as indicated in ICDD card \# 22-0153, with no impurity peaks being observed. The occurrence of strain will lead to the disturbance of the centro-symmetric environment around the $\mathrm{Nd}^{3+}$ center and the violation of the parity selection rule, thereby resulting in the enhanced photoluminescent efficiency. Scanning electron microscopy showed that the prepared samples mainly consist of solid particles with a mean size of around $1 \mu \mathrm{m}$. Energy dispersive $\mathrm{x}$ ray spectoscopy (EDS) analysis confirmed the presence of all the elements, including trace amounts of the $\mathrm{Nd}^{3+}$-doped compositions.

Fig. 2 shows the diffuse reflectance spectra of the prepared perovskite oxides. The high-resolution spectra of the transitions corresponding to $\mathrm{Nd}^{3+}$ are illustrated in Fig. 3. The valenceto-conduction band edges are located at $335 \mathrm{~nm}$ for all the samples. The band edges are nearly the same for these compositions, with only minor shifts if any. It should be noted that the wavelengths of these band edges are consistent with the peaks in the excitation spectra of the samples shown in Fig. 2. The absorption intensity due to the $4 \mathrm{f}^{2} 5 \mathrm{~d}^{1}-4 \mathrm{f}^{3}$ transition for

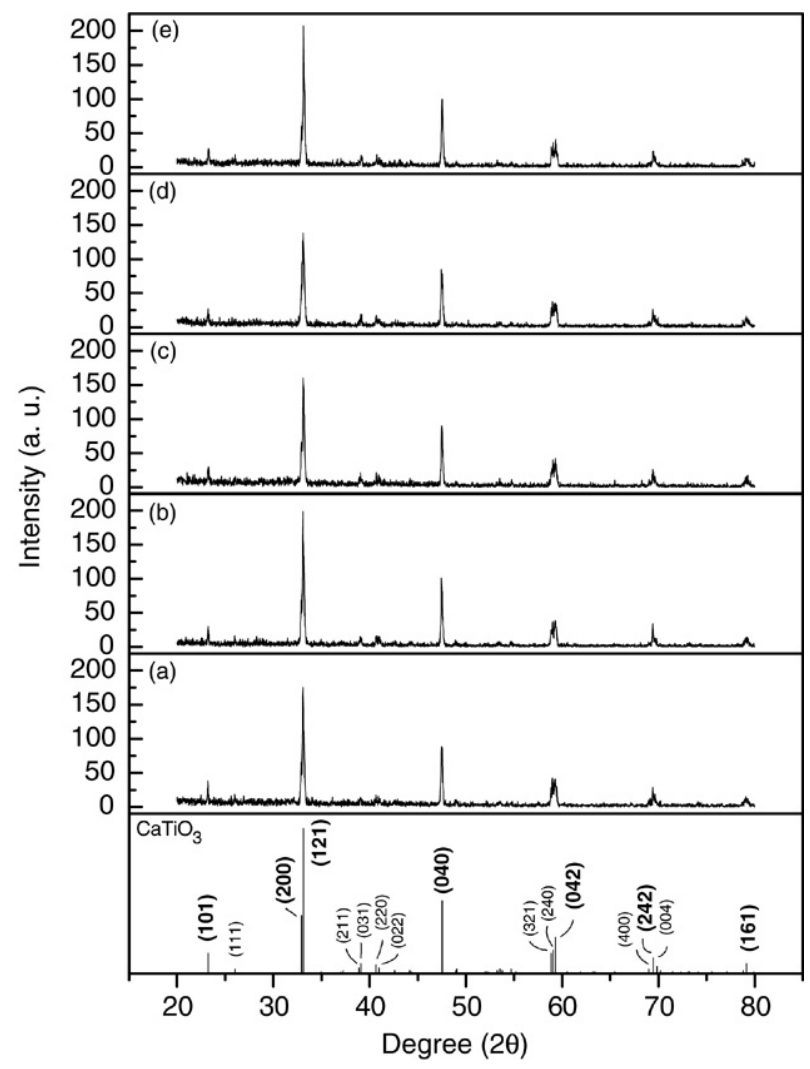

Fig. 1. Powder x-ray diffraction patterns of the samples at room temperature. All the samples show a pseudo-cubic to tetragonal structure with no detectable impurities: (a) $\left(\mathrm{Ca}_{0.97} \mathrm{Ba}_{0.01} \mathrm{Sr}_{0.02}\right) \mathrm{TiO}_{3}$, (b) $\mathrm{Nd}_{0.002}\left(\mathrm{Ca}_{0.97} \mathrm{Ba}_{0.01} \mathrm{Sr}_{0.018}\right) \mathrm{TiO}_{3}$, (c) $\mathrm{Nd}_{0.003}\left(\mathrm{Ca}_{0.97} \mathrm{Ba}_{0.01} \mathrm{Sr}_{0.017}\right) \mathrm{TiO}_{3}$, (d) $\mathrm{Nd}_{0.004}\left(\mathrm{Ca}_{0.97} \mathrm{Ba}_{0.01} \mathrm{Sr}_{0.016}\right) \mathrm{TiO}_{3}$, and (e) $\mathrm{Nd}_{0.005}\left(\mathrm{Ca}_{0.97} \mathrm{Ba}_{0.01}\right.$ $\left.\mathrm{Sr}_{0.015}\right) \mathrm{TiO}_{3}$.

$x=0.005$ seems to be greater than those for other samples. The intense emission for $x=0.005$ could probably be ascribed to the violation of the symmetry selection rule as a result of the greater asymmetry around $\mathrm{Nd}^{3+}$ ions. Other transitions corresponding to $\mathrm{Nd}^{3+}$ ions are located around $520 \mathrm{~nm} \mathrm{(}{ }^{2} \mathrm{~K}_{13 / 2}$, ${ }^{4} \mathrm{G}_{7 / 2},{ }^{4} \mathrm{G}_{9 / 2}$ with the ground state of $\left.{ }^{4} \mathrm{I}_{9 / 2}\right)$ and $590 \mathrm{~nm}\left({ }^{4} \mathrm{G} 5 / 2\right.$, ${ }^{2} \mathrm{G}_{7 / 2}$ with the ground state of ${ }^{4} \mathrm{I}_{9 / 2}$ ), and these transitions are shown in Fig. 3. Since the dominant transition is the band edge at $335 \mathrm{~nm}$, this transition was taken as the main energy value for our excitation studies.

Fig. 4 depicts the excitation spectra monitored at $612 \mathrm{~nm}$ along with the emission spectra excited at $335 \mathrm{~nm}$ for the $\mathrm{Nd}^{3+}$ doped $(\mathrm{Ca}, \mathrm{Ba}, \mathrm{Sr}) \mathrm{TiO}_{3}$ samples. The sample without $\mathrm{Nd}$-ion doping $\left(\left(\mathrm{Ca}_{0.97} \mathrm{Ba}_{0.01} \mathrm{Sr}_{0.02}\right) \mathrm{TiO}_{3}\right)$ did not have any luminescent properties. The red luminescence intensity increases with the substitution amount of $\mathrm{Nd}^{3+}$, which is possibly due to the promotion of the transitions allowed at the band edge by disturbing the centro-symmetric condition around the $\mathrm{Nd}^{3+}$ metal center in the perovskite environment [9]. In contrast to the excitation spectra of Pr-doped $\mathrm{CaTiO}_{3}$, those of the samples in this study show only a single peak at $335 \mathrm{~nm}$ without any shoulders [10]. Under UV excitation, the spectroscopic behavior of $\mathrm{Nd}^{3+}$-doped calcium titanates can be compared to that of semiconductors having large band gaps $[11,12]$. 


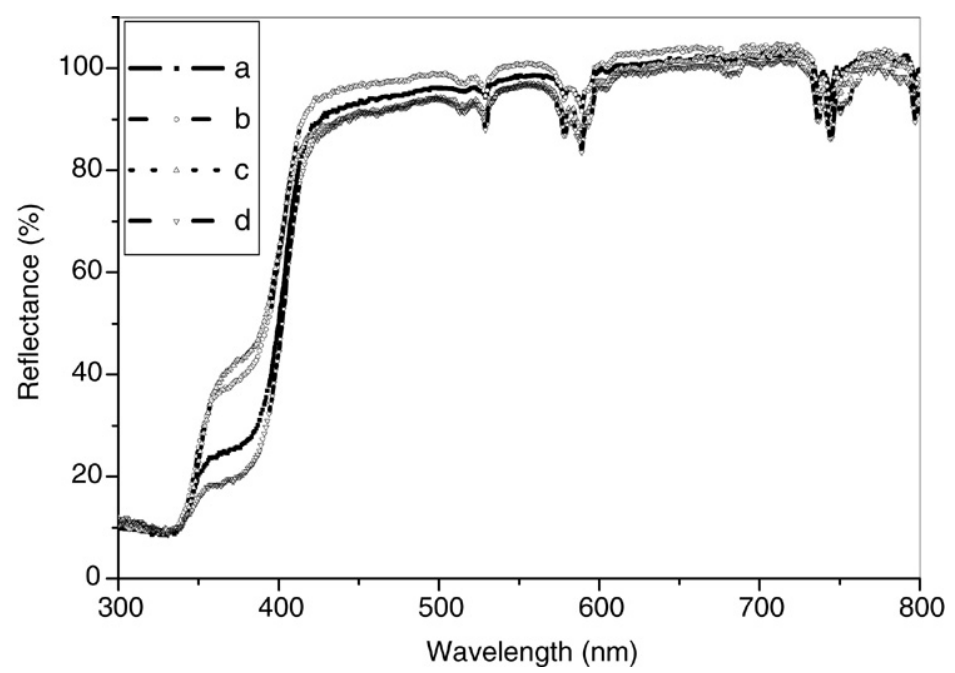

Fig. 2. Diffused reflectance spectra of the samples with various degrees of neodymium substitution: (a) $\mathrm{Nd}_{0.002}\left(\mathrm{Ca}_{0.97} \mathrm{Ba}_{0.01} \mathrm{Sr}_{0.018}\right) \mathrm{TiO}_{3}$, (b) $\mathrm{Nd}_{0.003}\left(\mathrm{Ca}_{0.97} \mathrm{Ba}_{0.01} \mathrm{Sr}_{0.017}\right) \mathrm{TiO}_{3}$, (c) $\mathrm{Nd}_{0.004}\left(\mathrm{Ca}_{0.97} \mathrm{Ba}_{0.01} \mathrm{Sr}_{0.016}\right) \mathrm{TiO}_{3}$, and (d) $\mathrm{Nd}_{0.005}\left(\mathrm{Ca}_{0.97} \mathrm{Ba}_{0.01} \mathrm{Sr}_{0.015}\right) \mathrm{TiO}_{3}$.

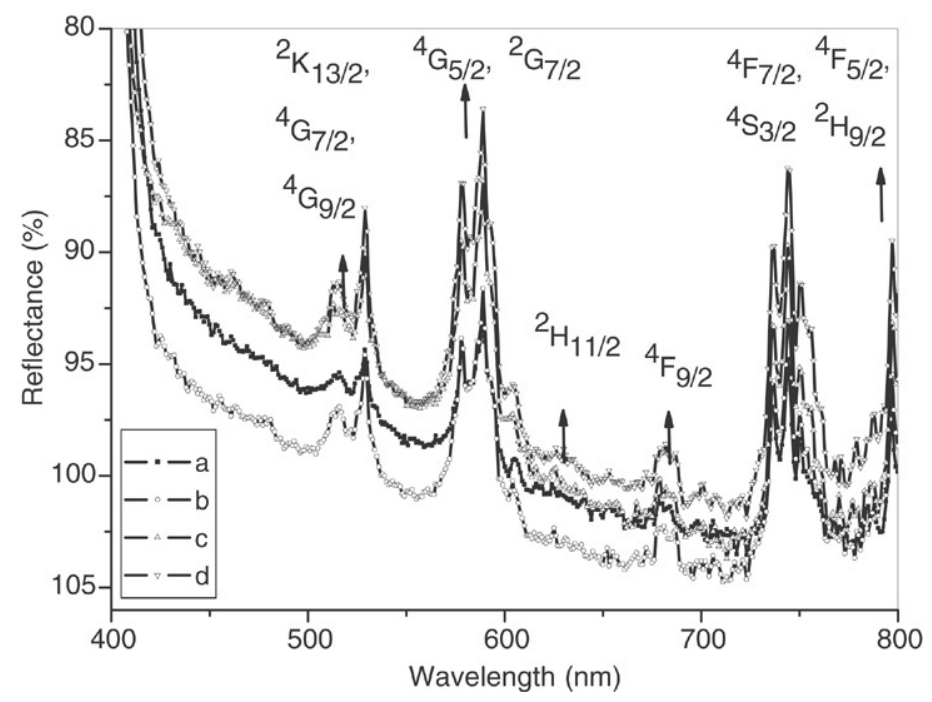

Fig. 3. High-resolution spectra of the transitions corresponding to $\mathrm{Nd}^{3+}$ with the composition (a) $\mathrm{Nd}_{0.002}\left(\mathrm{Ca}_{0.97} \mathrm{Ba}_{0.01} \mathrm{Sr}_{0.018}\right) \mathrm{TiO}_{3}$, (b) $\mathrm{Nd}_{0.003}\left(\mathrm{Ca}_{0.97} \mathrm{Ba}_{0.01}\right.$ $\left.\mathrm{Sr}_{0.017}\right) \mathrm{TiO}_{3}$, (c) $\mathrm{Nd}_{0.004}\left(\mathrm{Ca}_{0.97} \mathrm{Ba}_{0.01} \mathrm{Sr}_{0.016}\right) \mathrm{TiO}_{3}$, and (d) $\mathrm{Nd}_{0.005}\left(\mathrm{Ca}_{0.97} \mathrm{Ba}_{0.01} \mathrm{Sr}_{0.015}\right) \mathrm{TiO}_{3}$.

In the case of titanates, this UV excitation generates $\mathrm{O}(2 \mathrm{p})-\mathrm{Ti}(3 \mathrm{~d})$ and/or $\mathrm{Nd}^{3+}$ (4f) $\mathrm{Ti}(3 \mathrm{~d})$ charge transfers and therefore produces electron-hole pairs. An electron can be captured into the excited $4 \mathrm{f}$ shell of a $\mathrm{Nd}_{\mathrm{Ca}^{2+}}^{3+}$ center acting as an electron trap. Concomitantly, the hole lying in the valence band can be captured elsewhere in the materials either in the form of oxygen vacancies or the cationic compensators $\mathrm{Ti}_{\mathrm{Ti}^{3+}}^{4+} \cdot[13]$. This electron-hole recombination will radiate in nature, and hence we observe the photoluminescence. The CIE diagram of the sample doped with $x=0.005$ is illustrated in the inset of Fig. 4. The color coordinates of all doped samples are found to be around $(0.679,0.312)$, which falls within the red region of the 1931 CIE diagram.

The brightness efficiencies of the samples were calculated compared to that of the commercial phosphor $\mathrm{Y}_{2} \mathrm{O}_{2} \mathrm{~S}: \mathrm{Eu}^{3+}$, according to the reported procedure under the same excitation conditions [14]. The reported quantum efficiency value for $\mathrm{Y}_{2} \mathrm{O}_{2} \mathrm{~S}: \mathrm{Eu}^{3+}$ is $60 \%$. The relative quantum efficiency based on the integrated area emission of the sample $\mathrm{Nd}_{0.005}\left(\mathrm{Ca}_{0.97}, \mathrm{Ba}_{0.01}, \mathrm{Sr}_{0.015}\right) \mathrm{TiO}_{3}$ is $10.8 \%$. The quantum efficiency calculated using this approach gives a reasonable idea of the actual quantum efficiency.

To the best of our knowledge, this is the first report where strong visible emission from $\mathrm{Nd}^{3+}$ has been observed. The emission properties of the transitions corresponding the bandedge emission will prove to be vital in deciding the applicability of this compound to various display applications.

\section{Conclusions}

Neodymium-ion doping in the host perovskite $\mathrm{Nd}_{x}$ $\left(\mathrm{Ca}_{1-x-y-z}, \mathrm{Ba}_{y}, \mathrm{Sr}_{z}\right) \mathrm{TiO}_{3}$ was found to result in efficient red luminescence. All the synthesized materials have a cubic structure. The excitation at the band edge of the host at $335 \mathrm{~nm}$ generates an intense red emission with a quantum efficiency of $10.8 \%$ for $\mathrm{Nd}_{0.005}\left(\mathrm{Ca}_{0.97} \mathrm{Ba}_{0.01} \mathrm{Sr}_{0.015}\right) \mathrm{TiO}_{3}$ relative to the commercially used red phosphor. The symmetry around the 


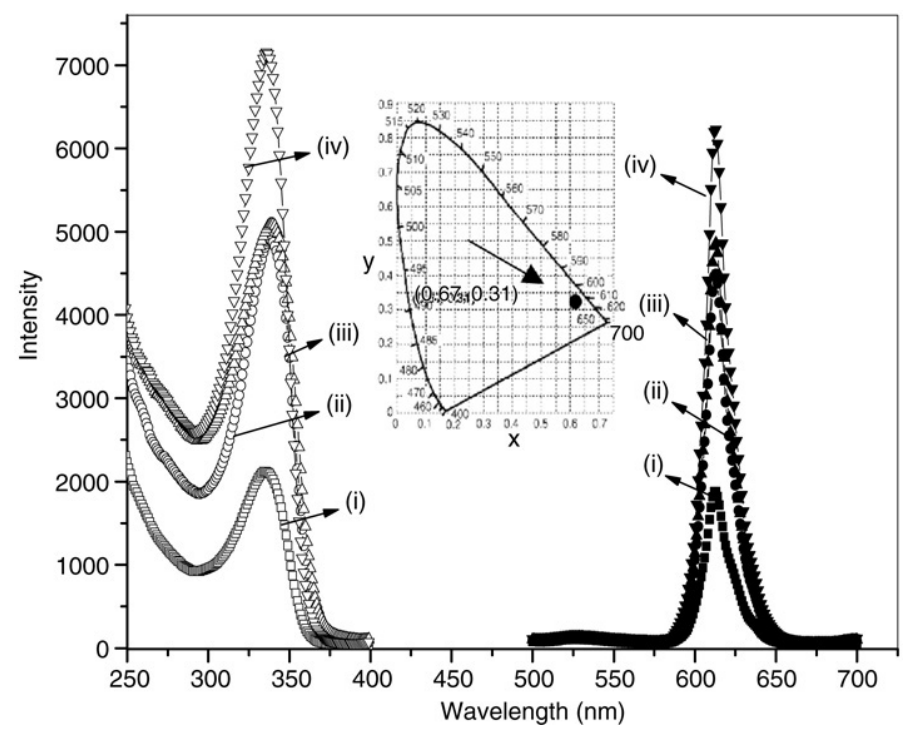

Fig. 4. Photoluminescence excitation and emission spectra of the samples (a) $\mathrm{Nd}_{0.002}\left(\mathrm{Ca}_{0.97} \mathrm{Ba}_{0.01} \mathrm{Sr}_{0.018}\right) \mathrm{TiO}_{3},(\mathrm{~b}) \mathrm{Nd}_{0.003}\left(\mathrm{Ca}_{0.97} \mathrm{Ba}_{0.01} \mathrm{Sr}_{0.017}\right) \mathrm{TiO}_{3}$, (c) $\mathrm{Nd}_{0.004}\left(\mathrm{Ca}_{0.97} \mathrm{Ba}_{0.01} \mathrm{Sr}_{0.016}\right) \mathrm{TiO}_{3}$, and (d) $\mathrm{Nd}_{0.005}\left(\mathrm{Ca}_{0.97} \mathrm{Ba}_{0.01} \mathrm{Sr}_{0.015}\right) \mathrm{TiO}_{3}$. The inset shows the CIE diagram of $\mathrm{Nd}_{0.005}\left(\mathrm{Ca}_{0.97} \mathrm{Ba}_{0.01} \mathrm{Sr}_{0.015}\right) \mathrm{TiO}_{3}$.

emitting center is more distorted with greater substitution by neodymium ions, resulting in violation of the parity selection rule and thereby producing the red emission.

\section{References}

[1] R. Bazzi, A. Brenier, P. Perriat, O. Tillement, J. Lumin. 113 (2005) 161.

[2] M.-L. Feng, J.-G. Mao, J. Alloys. Comp. 388 (2005) 23.

[3] I.G. Rubio, J.A. Pardo, R.I. Merino, R. Cases, V.M. Orera, J. Lumin. 86 (2000) 147.

[4] P.S. Peijzel, P. Vergeer, A. Meijerink, M.F. Reid, L.A. Boatner, G.W. Burdick, Phys. Rev. B. 71 (2005) 045116.

[5] H. Mizoguchi, P.M. Woodward, C.-H. Park, D.A. Keszler, J. Am. Chem. Soc. 126 (2004) 9796.
[6] K. Ait-Ameur, D. Louhibi, T. Kerdja, Opt. Commun. 217 (2003) 351.

[7] G. Dominiak-Dzik, W. Ryba-Romanowski, S. Golab, M. Berkowski, Spectrochim. Acta Part A 54 (1998) 2051.

[8] J.B. Goodenough, J. Appl. Phys. 81 (1997) 5330.

[9] C.H. Park, C.I. Jeon, B.Y. Yu, H. Choi, H.S. Bae, C.H. Kim, C.H. Pyun, J. SID 6 (1998) 77.

[10] T. Jyomen, R. Sakamoto, N. Sakamoto, S. Kunugi, M. Itoh, Chem. Mater. 17 (2005) 3200.

[11] H. Zimmermann, R. Boyn, Phys. Status Solidi (b) 139 (1987) 533.

[12] H. Przybylinska, K. Swiatek, A. Sapor, A. Suchoki, M. Godlewski, Phys. Rev. B 40 (1989) 1748.

[13] E.R. Vance, R.A. Day, Z. Zhang, B.D. Begg, C.J. Ball, M.G. Blackford, J. Solid State Chem. 124 (1996) 77.

[14] A.A. Bol, A. Meijerink, J. Phys. Chem. B 105 (2001) 10197. 